Bull. Fac. Agric., Cairo Univ., 68: 37-44(2017).

\title{
KNOWLEDGE AND IMPLEMENTATION DETERMINANTS OF THE MARWA AND MESQA COMMITTEE GOAL'S IN SOME VILLAGES OF WATER MANAGEMENT REFORM PROGRAM - KAFR EL-SHEIKH GOVERNORATE,EGYPT
}

(Received: 28.12.2016)

By

\author{
M. S. A. Elsabbagh and H. M. Farag*
}

\begin{abstract}
Human Development \&Economics Department Faculty of Fish Resources, Suez University.
* Agriculture Extension \& Rural Development Research Institute, Agriculture Research Center, Giza, Egypt.
\end{abstract}

\begin{abstract}
The current study aimed to identify the knowledge and implementation variables of the Marwa and Mesqa committee members about the committee goals in rational use of irrigation water, identify the problems facing committee members, and finally propose skills and knowledge program that achieve rational use of irrigation water. The study was carried out in Kafr El-Sheikh Governorate in water management reform program area in 25 villages ( 5 villages from each of the following centers: Kafr El-Sheikh, Sidi Salem, Qaleen, Riyadh, Desouk), where 2 marwa or mesqa were selected from each village. Three of each committee members (Chairman of the Committee, the pump operator, member of the Committee) were chosen, to make the total number of respondents 150. Data were collected by personal interview using a designed questionnaire in August of 2016.

The main results of this study were that there was significant relationship between the knowledge and implementation of committee member goal's to rationalize the use of irrigation water in agriculture terms which was, 0.861 in a direct correlation that the higher the degree of knowledge increased the degree of adoption and implementation and then modifying the behavior of the use of irrigation water, depending basically on the variables "level of education of the respondents, the degree of membership in the rural associations, the degree of attending the meetings of these associations, and cosmopolitans in irrigation methods. The problems facing the committees members in rationalizing the use of irrigation were divided into high-impact problems ranging between "85; $70 \% "$ the lack of maintenance centers of irrigation stations, lack of water-saving irrigation throughout the year. The problems with the medium effect average ranged between "69: 53\%" which was the "lack of regular periodic maintenance of the machines, lack of training of the members of the Commission's Governing Council on the tasks assigned to them and not activated. The problems with low impact ranging between" 43: 28\% "which was" the collapse of bridges, over some canals whether major or subsidiary, poor knowledge of the members of the board of Directors and farmers of agricultural practices and water conservation at the field level. We propose some training programs for the members of committees to acquire some knowledge, develop their skills, whether planning or technical modification of some wrong behavior.
\end{abstract}

Key words: marwa committees, rational water use, knowledge. 


\title{
محددات معرفة وتنفيذ أعضاء لجان المراوي والمساقي لأهدافها بيعض قري إنماري

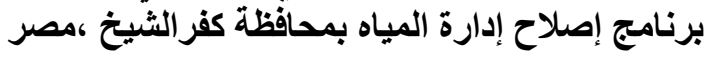

\section{محمد صابر عبدالحميد الصباغ - حنان مكرم فرج*}

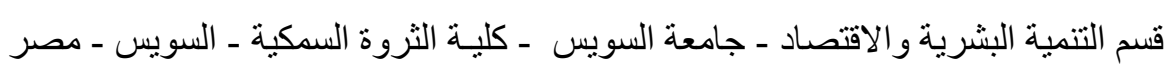

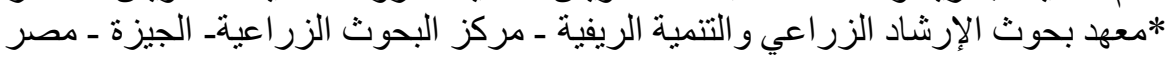

\begin{abstract}
ملخص

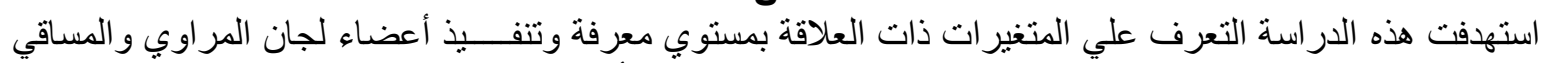

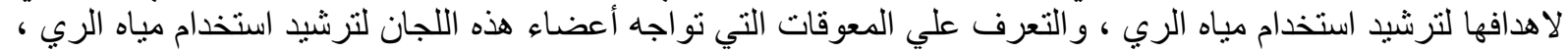

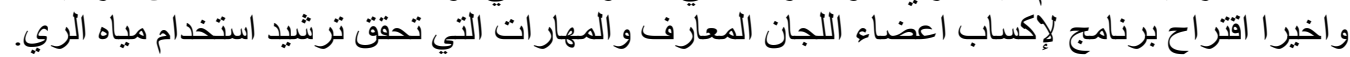

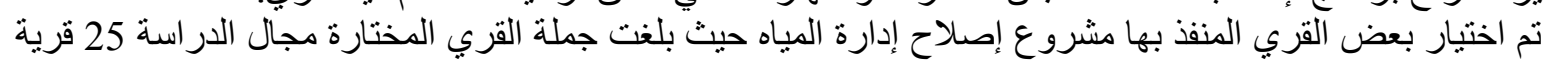

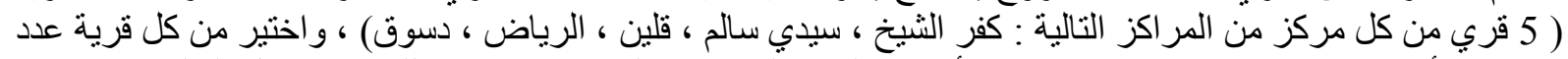

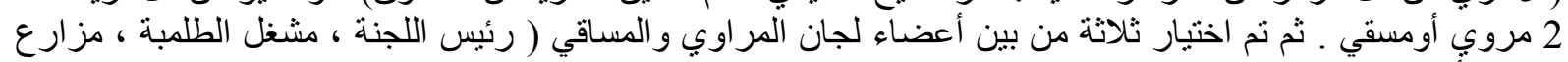

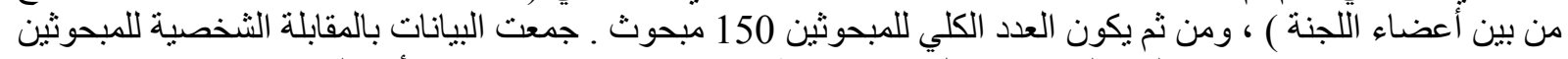

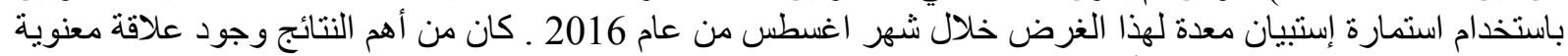

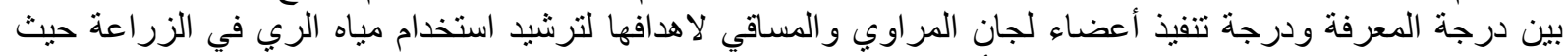

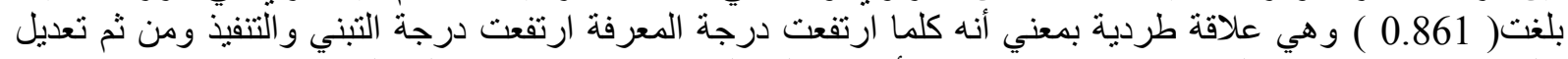

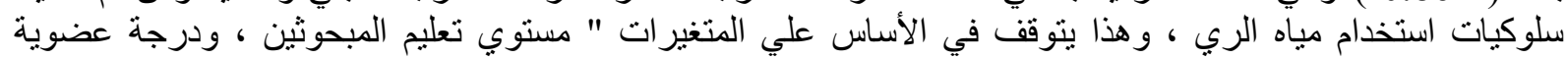

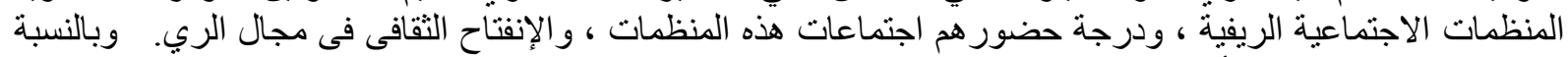

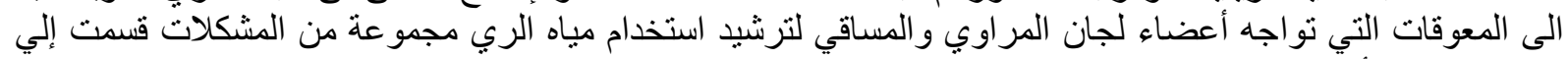

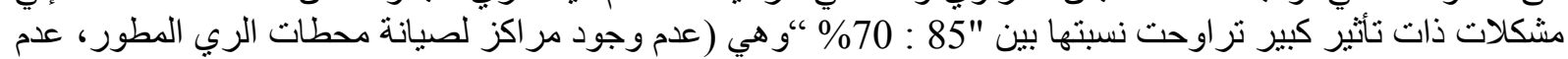

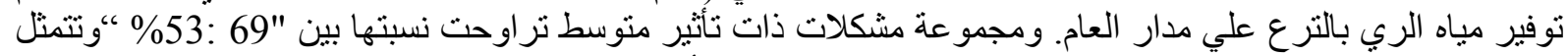

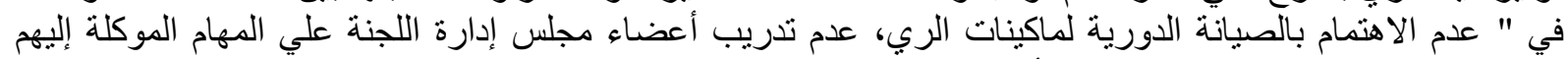

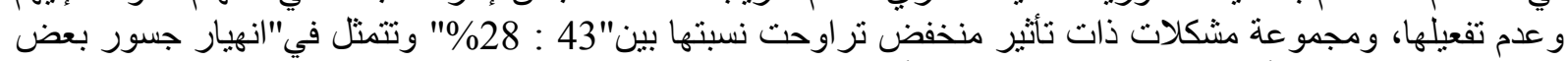

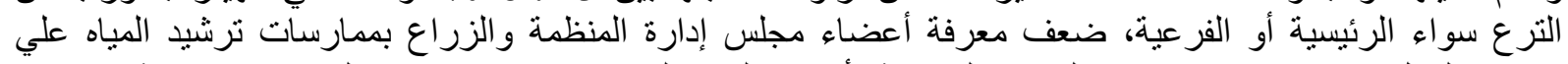

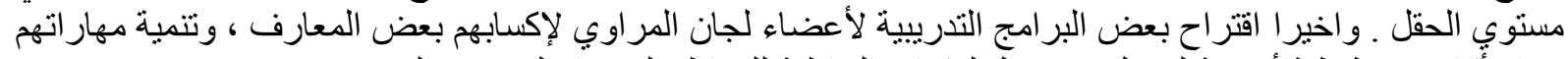

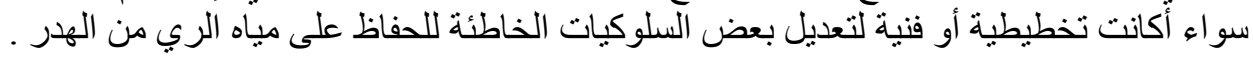

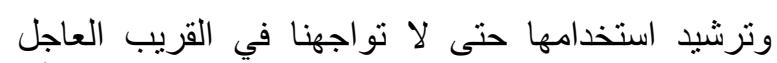

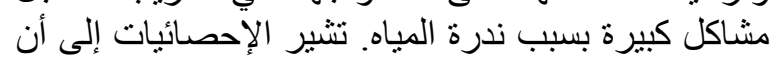

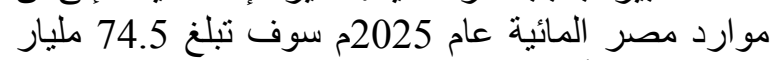

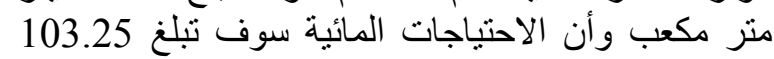
مليار متر مكعب بسبب الزيادة السكان السكانية و على ذلى ذلك سوف

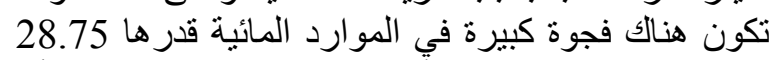

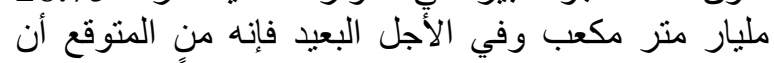

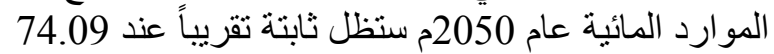

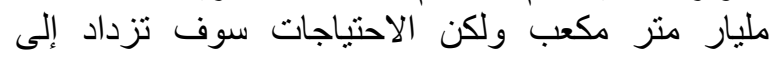

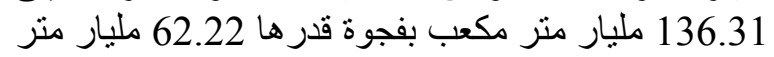

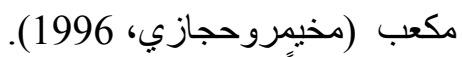
وحرصاً من الدولة على تحقيق أقصى استفادة ممكنة

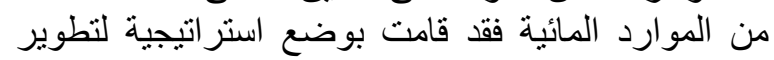

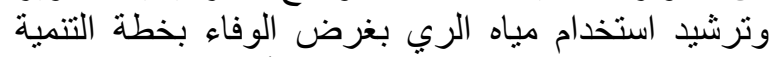

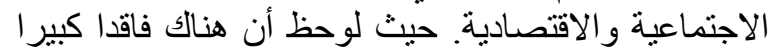

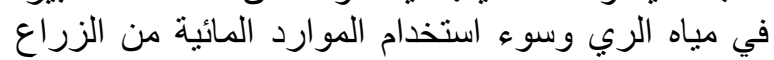

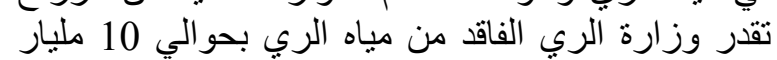

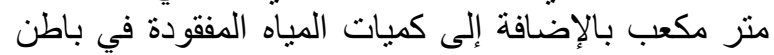

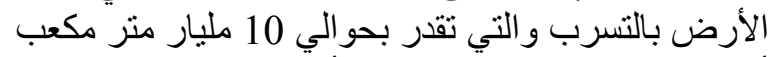
أخرى وتقدر إحدى الدراسات الأمريكية إجمالي الفقد في

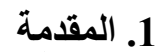

تعتبر التنمية الزراعية مطلباً أساسياً وملجاً لجميع الجيا

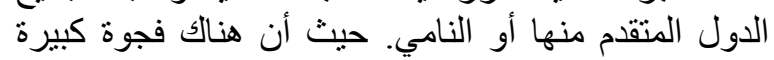

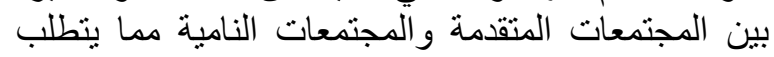

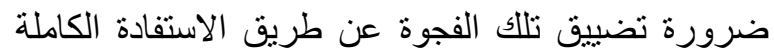

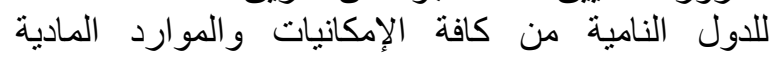

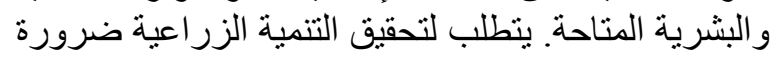

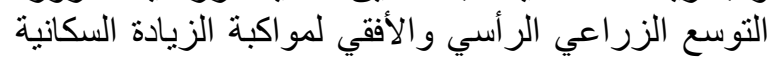

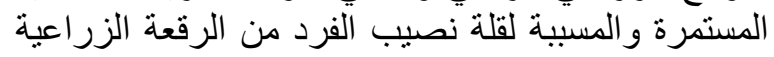
حيث يصل متوسط نصيب الفرد من تلاك الرقبة الرقعة 0.12

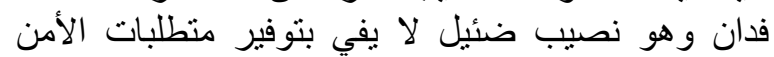

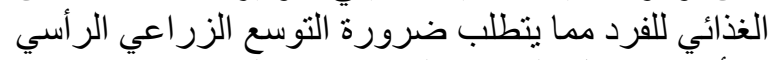

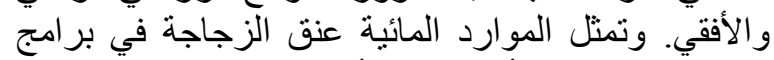

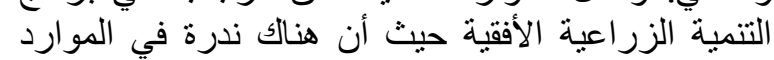

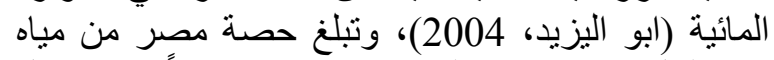

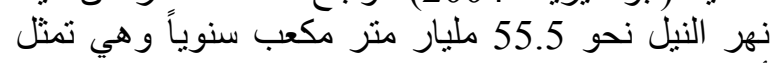

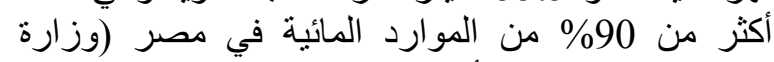

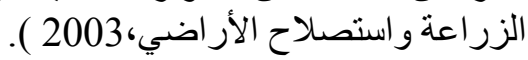

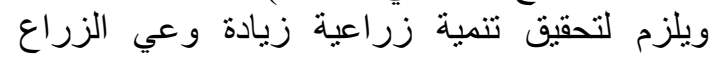
بأهمية المياه وضرورة الحفاظ عليها وتقليل ألفاقد منها 
وفي دراسة منصور وبالي (1999) التي استهدفت

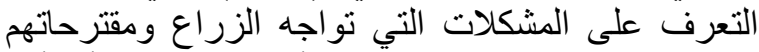
لإنجاح مشروع التطوير، وتبرز أهم النتائج في أن أهم أهم أنماع

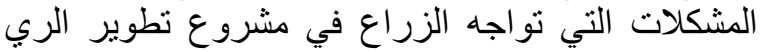

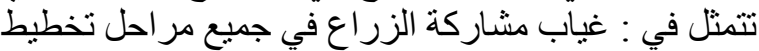

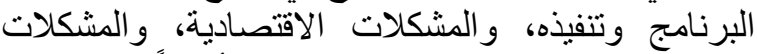

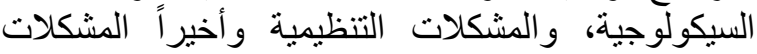

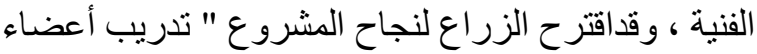

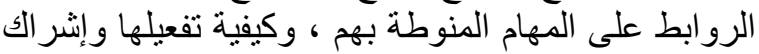

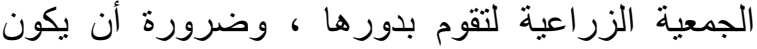
التطوير وفق حاجات ور غبات الزية المستفيدين به.

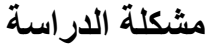

يمكن من العرض السابق بلورة مشكلة الدراسة في

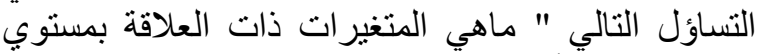

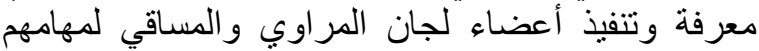

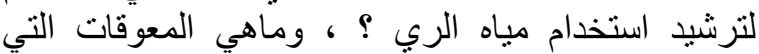

تو اجهـم لتحقيق هذه المهام ؟ الرئ. أهداف الدراسة التهية

يمكن مما سبق صباغة الهدف العام للار اسة في التعرف

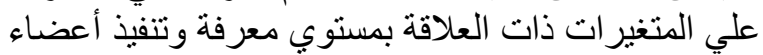
لجان المراوي أو المساقي لاهدافها لافيا لترشيد استخدام مياه

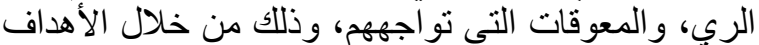

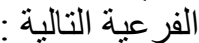

1 - التعرف علي مستوي معرفة ، وتنفيذ أعضاء لجان التران

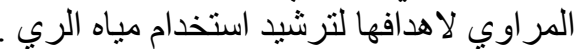

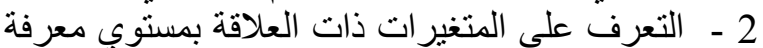

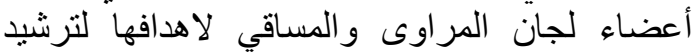

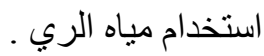

3 - التعرف علي المتغيرات ذات الريات العلاقة بمستوي تتفيذ أعضاء لجان المر اوى و المساقي لاهدافها لتا لترشيد استخدام

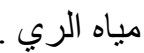

4- التعرف علي المعوقات التي تواجه أعضاء لجان العبان

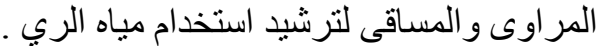

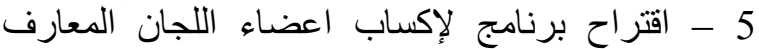
و المهار ات لتعديل سلوكياتهم التي تحقق ترشيد اعتياء التخدام

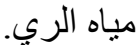
الفروض البحثية 1- تم لتحقيق هدف الدئة الداسة الثاني صياغة الفرض النظري

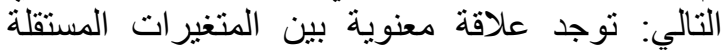

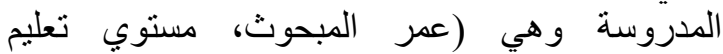

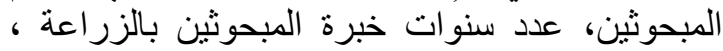

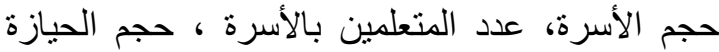

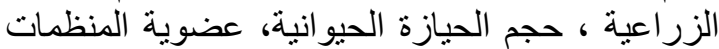

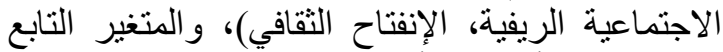
و هو معرفة الأعضاء لأهدافها. 2 - تم لتحقيق هدف الاراسة الثالث صياغة الفرض النظري التالي: توجد علاقة معنوية بين المتئية التغيرات

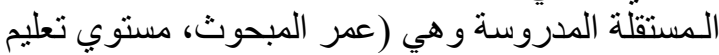

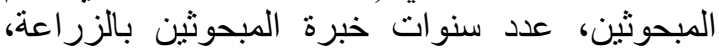
حجم الأسرة، عدد المتعلمين بالأسرة، حجم الحيازة بالزة
مياه الري بحوالي 30 مليار منر مكعب سنوياً وهي كمية تكفي لزراعة حوالي 2.8 مليون فدان (ابو اليزيد ،

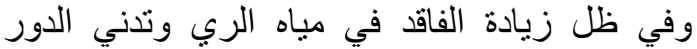

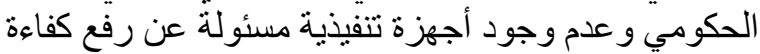

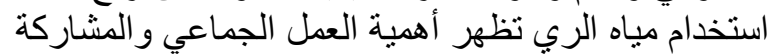

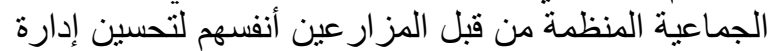

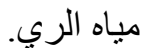
ويذكر شرشر (2005) نقلاً عن أبو اليزيد (2004)أن

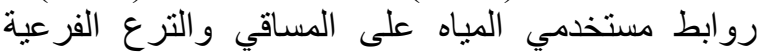

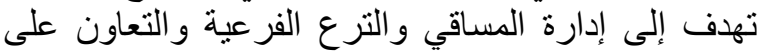

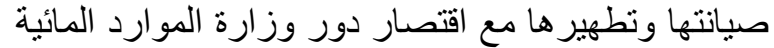

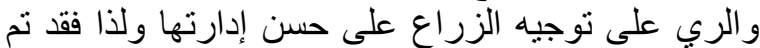

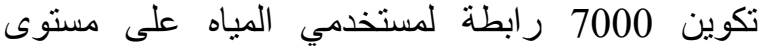

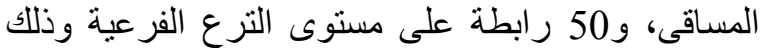

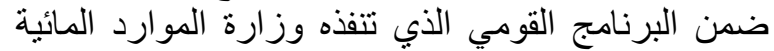
و الري منذ عام 1984م لتطوير 3.5 مليون فدان حنى عام التهري 2017م بما يسهم في توفير 3 مليار متر مكعب من مني مياه الري شرشر (2005). ولّللك كان من الأهمية بمكان الوقوف على محددات

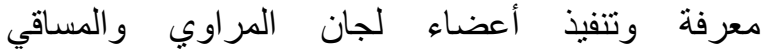

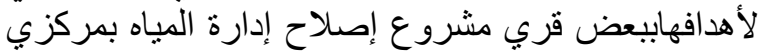

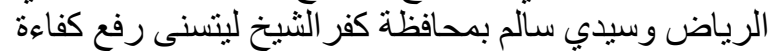

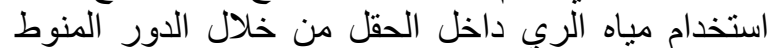

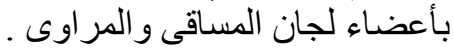

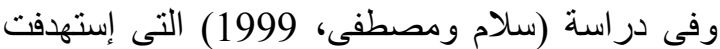

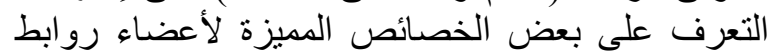

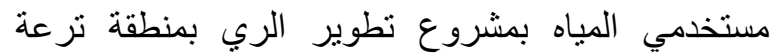

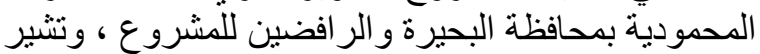

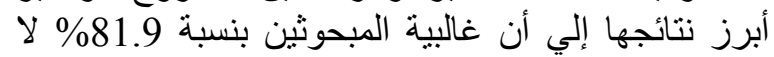

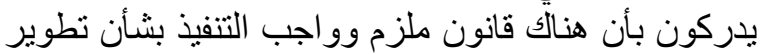

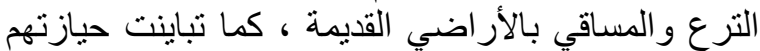

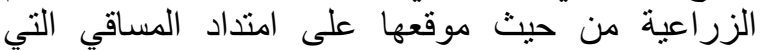

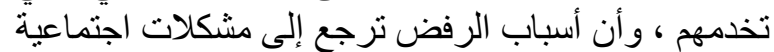

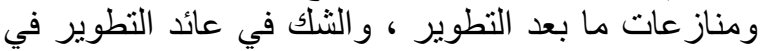
مقابل تكاليف تنفيذه ، و التخوف من مشكلات مرحلة التة التنفيذ

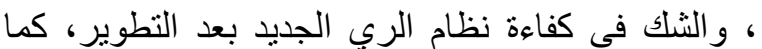
أثنارت النتائج بوجود علاقة نظة معنوية بين أعمار المبحوثين

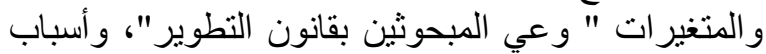
نقص المعرفة بمشروع التطوير و الثنك في عائده في مقابل ولئ

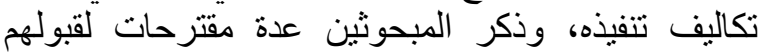
المشاركه الفعالة في جهود تنفيذ التطوير تتلخص فئن في ضمان عدالة توزيع تكاليف التطوير التي سيتحملها الفذان

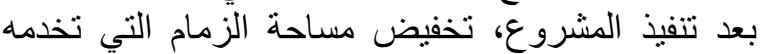

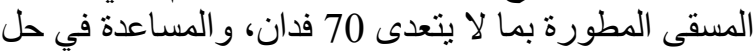

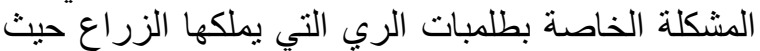

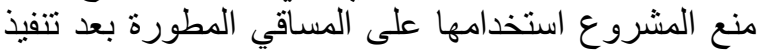

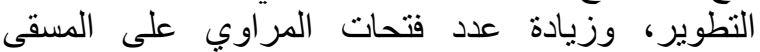

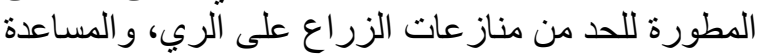

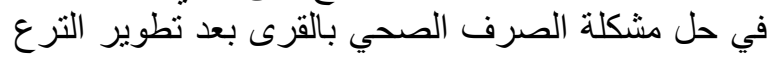

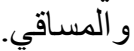


هوموضح بالجدول (1) التوزيع التكراري لمستويات معرفة المبحوثين لأهداف اللجنة . مالجئ 2- درجة تنفيذ أعضاء لجان المراوي أو المساقي لأهدافها

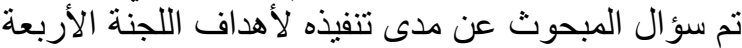

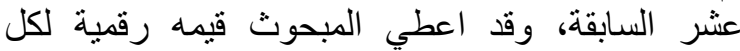

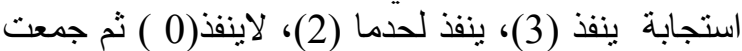
استجابة كل مبحوث عن مدي تنفيذه لأهداف اللجنة، وقدا لوند

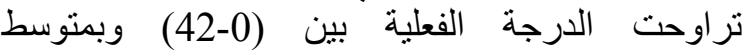

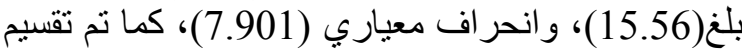

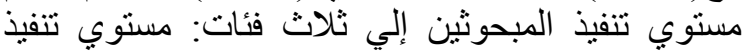

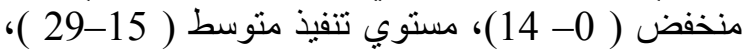
مستوي تنفيذ مرتفع ( 10- 42)، كما هوموضح بالئ بالجدول (1) التوزيع التكر اري لمستويات التنفيذ .

\begin{tabular}{|c|c|c|c|c|}
\hline \multicolumn{5}{|c|}{ 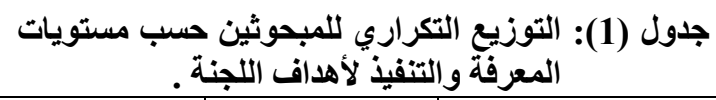 } \\
\hline \multicolumn{2}{|c|}{ التنفيذ } & \multicolumn{2}{|c|}{ المعرفة } & المعرفة والتنفيذ الفئات \\
\hline 48.0 & 70 & 36.0 & 54 & $\begin{array}{c}14-0 \\
\text { ( مستوي منخفض ) }\end{array}$ \\
\hline 51.3 & 79 & 63.3 & 95 & $\begin{array}{c}29-15 \\
\text { (مستوي متوسط) }\end{array}$ \\
\hline 0.7 & 1 & 0.7 & 1 & $\begin{array}{c}42-30 \\
\text { (مستوي مرتفع ) }\end{array}$ \\
\hline $\mathbf{0 0 . 0}$ & 150 & $\mathbf{0 0 . 0}$ & 150 & جملة \\
\hline
\end{tabular}

و الجدول (2) يبين المتغيرات المدروسة المستقلة

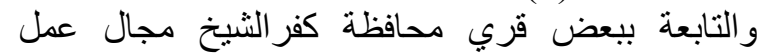
مشروع إصلاح إدارة المياة. ثناتيا: المتغيرات المستقلة وهي: عمر المبحوث (بالسنة)؛

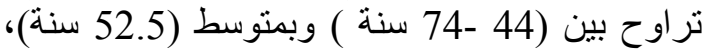

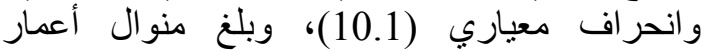

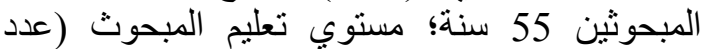

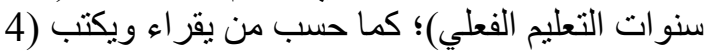

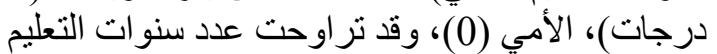

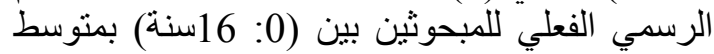

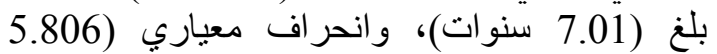

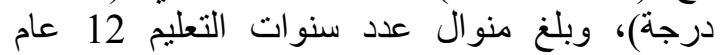

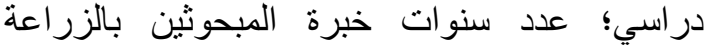

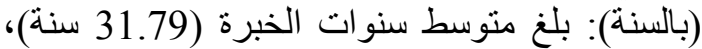
و انحر اف معياري (12.4) وتر اوحت الدرجة الدئ الفعلية

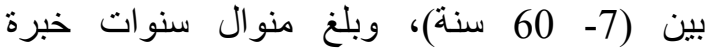
المبحوثين 30 سنة. حجم الأسرة (بالعدد): تراوح العن العدد

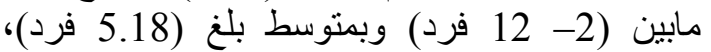

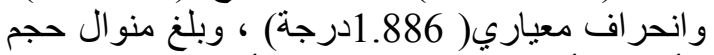

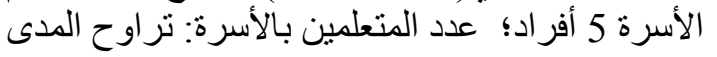

الزراعية، حجم الحيازة الحيوانية، عضوية المنظمات الزية الاجتماعية الريفية، الإنفتاح الثقافي) ودرجة تلفيذ الإنية

الأعضاء لأهدافها الريفة

\section{2. 2 - 2 الطريقة البحثية}

تم إجر اء هذه الدراسة وفق المجالات الثلاث التالية :

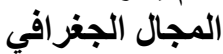
تم اختيار بعض القري المناف المنف بها مشروع إصلاح إدارة

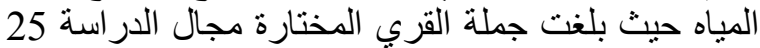

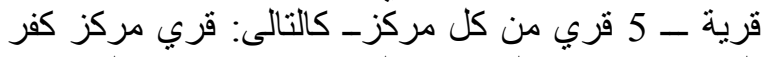

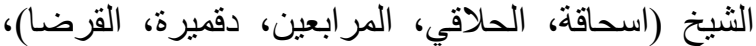
قري مركز سيدي سالم (تبدا، الهندسة، أبوأحمد، منشاة العزية

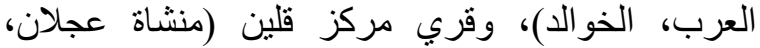

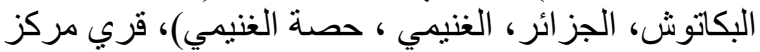

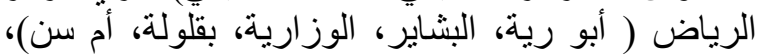

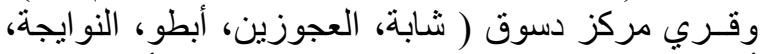

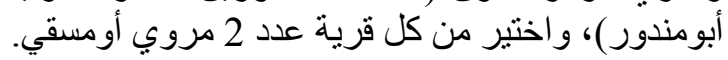

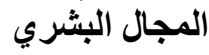
تم اختيار ثلاثة من بين أعضاء لجان لمان المراوي

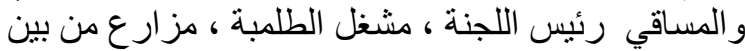
أعضاء اللجنة ومن ثم يكون العدد الكلي للمبحوثين 150

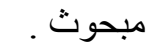
المجال الزمني

تم جمع البيانات عن طريق الزمئ المقابلة الثخصية للمبحوثين باستخدام استمارة إستبيان خلال شهر اغسطس الشع

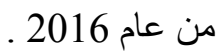
قياس متغيرات الار استة

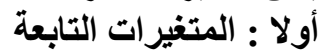

1- معرفة أعضاء لجان التابعة المراوي والمساقي لأهدافها

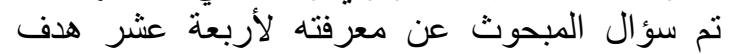

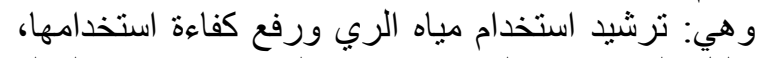

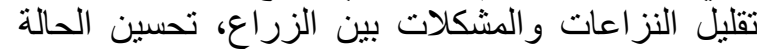

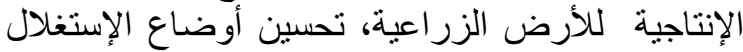

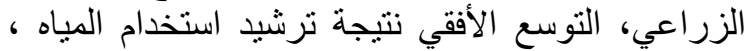

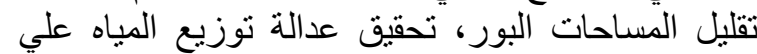
المسقي، صيانة المسقي المطورة، تشغيل المضخات المنات علي المياه

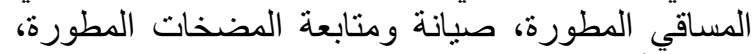

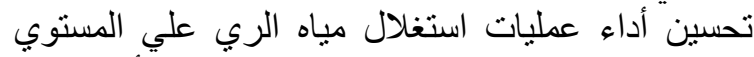

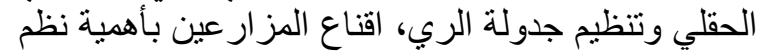

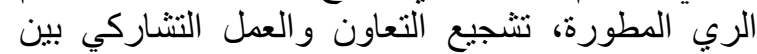

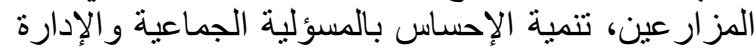

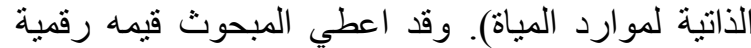

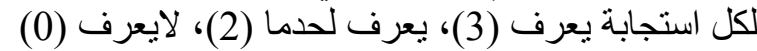

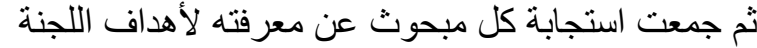

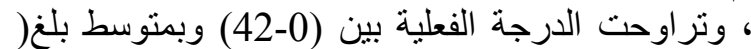

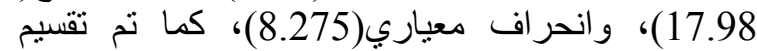

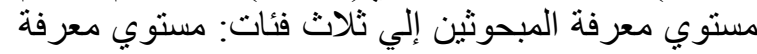

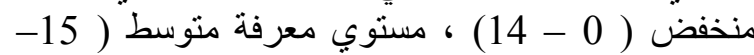
29)، مستوي معرفة مرتفع ( 30 - 42) ، منتوي (كما 
جدول (2): الوصف الإحصائى لبعض المتغيرات المستقلة والتابعة المدروسة ببعض قري محافظة كفرالثيخ مجال عمل مشروع إصلاح

\begin{tabular}{|c|c|c|c|c|c|c|}
\hline 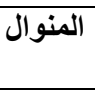 & الفعلي & درجة & درجة & الإنحرياري & الحستوسط & المتغيرات المستقلة/ المتغيرات التابعة \\
\hline 55 & 44 & 74 & 30 & 10.1 & 52.48 & عمر المبحوث \\
\hline 12 & 16 & 16 & $\mathbf{0}$ & 5.806 & 7.0 & مستوي تعليم المبحوثين "عدد سنوات التعليم" \\
\hline 30 & 53 & 60 & 7 & 12.41 & 31.79 & عدد سنوات خبرة المبحوثين بالزراعة \\
\hline 5 & 10 & 12 & 2 & 1,886 & 5.18 & حجم الأسرة \\
\hline 3 & 12 & 12 & $\mathbf{0}$ & 2.07 & 3.62 & عدد المتعلمين بالأسرة \\
\hline 72 & 542 & 552 & 10 & 68.27 & 56.31 & حجم الحيازة المزرعية \\
\hline 1.93 & 10.3 & 10.3 & $\mathbf{0}$ & 1.5 & 1.6 & حجم الحيازة الحيوانية \\
\hline 2 & 6 & 6 & $\mathbf{0}$ & 1.342 & 3.42 & حيازة المبحوثين لبعض الآلات والأدوات الزراعية \\
\hline $\mathbf{0}$ & 17 & 17 & $\mathbf{0}$ & 3.457 & 3.48 & مستوي عضوية المبحوثين بالمنظمات الاجتماعية \\
\hline 2 & 10 & 10 & $\mathbf{0}$ & 3.46 & 4.566 & الاجتماعية حضور المبحوثين اجتماعات المنظمات \\
\hline 6 & 13 & 15 & 2 & 3.294 & 7.81 & درجة الإنفتاح الثقافي للمبحوثين في مجال الري \\
\hline 3 & 3 & 3 & $\mathbf{0}$ & 0.935 & 1.926 & تجديدية المبحوثين \\
\hline 28 & 42 & 42 & $\mathbf{0}$ & 8.275 & 17.98 & معرفة المبحوثين لأهداف لجنة المراوي \\
\hline 22 & 42 & 42 & $\mathbf{0}$ & 7.901 & 15.56 & تتفيذ المبحوثين لأهداف لجنة المراوي \\
\hline
\end{tabular}

المصدر : استمارة الإستبيان

حضورقيمة رقمية (3، 2، 1) لتدل على درجة

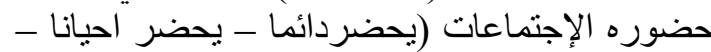

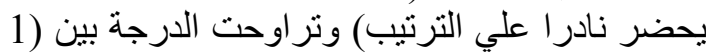

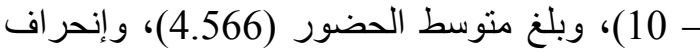

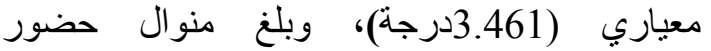
الإجتماعات 2 جلسة. الانفتاح الثقافي للمبحوثين في الثي

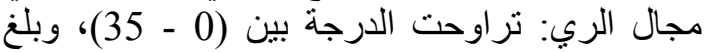

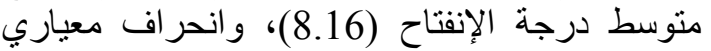
(6.087 درجة )، وبلغ منو ال درجة (8) الفتاح المبحوثين

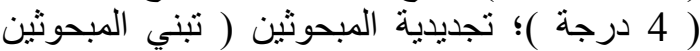

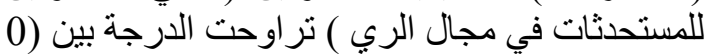

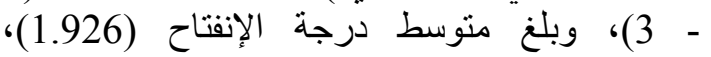
و انحر اف معياري (0.935 درجة)، وبلغ الإنغ منو ال درجة تجديدية المبحوثين ( 3 درجة (اندئ ) . الأساليب الإحصائية وحتي بمكن عرض نتائج الدراسة استخدم العرض الإسلة

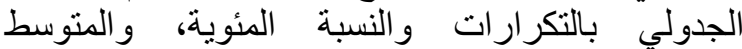

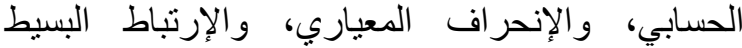
لبيرسون. ( بركات، والحرافي 2000 ).

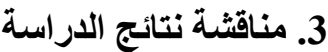

1.3. العلاقة بين المتغيرات المستقلة و التابعة المدروسة التهائة

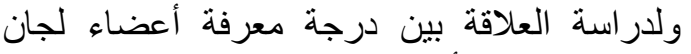
المراوي و المساقي لأهدافها والتي في مجموعها تعمل

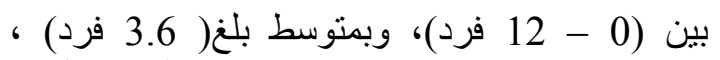

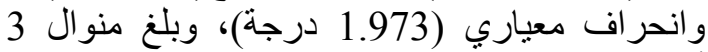

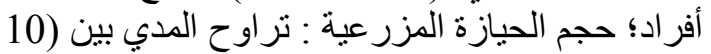

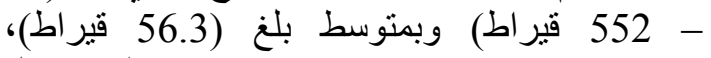

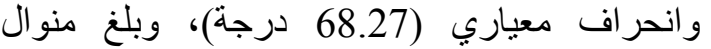

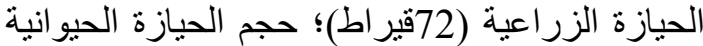
:تر اوح مدي حيازة الحيو انات بين (0 -

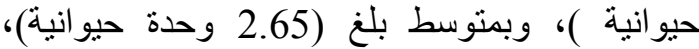

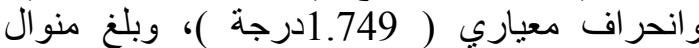

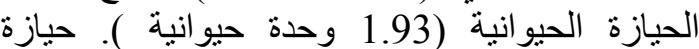

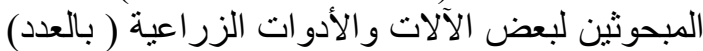

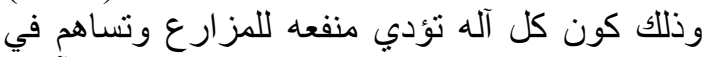

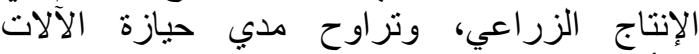

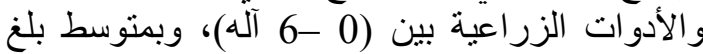

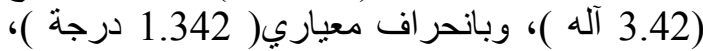

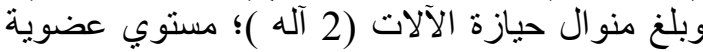

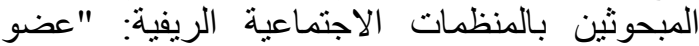
عادي، عضو مجلس إدارة، رئيس مجلس المبن إدارة،

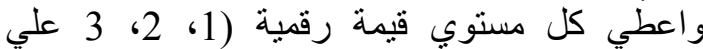

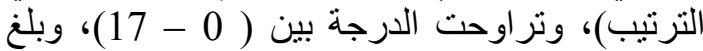

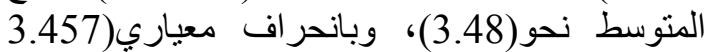

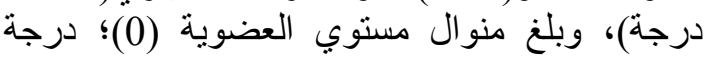
حضور المبحوثين اجتماعات المنظمات الاجنية التماعية درية الريفية التي هو عضو بها، وقد أعطي كل درجة الانية 
الحيازة الزر اعية، حجم الحيازة الحيو انية"، هذا بالنسبة الإبة الحفية للفرض الإحصائي الأول الزئه،

يتبين من هذه النتائج أن العلاقة المعنوئ الأنيه المتحصل

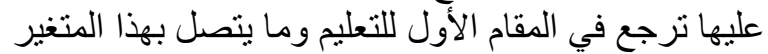

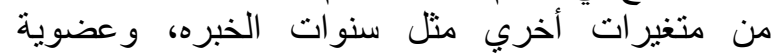

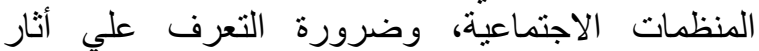

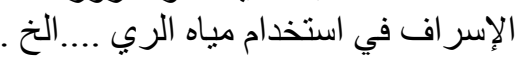
ثانيا : نتائج اختبار الفرض الإنير الإحصائي الثاني

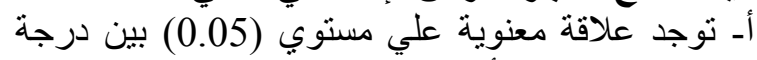

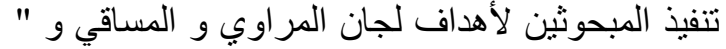

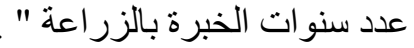
ب ـ توجد علاقة معنوية علي مستوي (0.01 ) بين درجة التهة

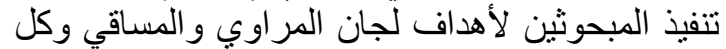

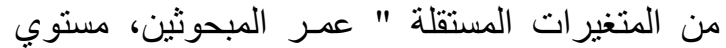

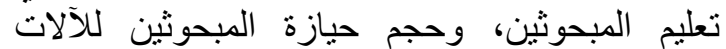

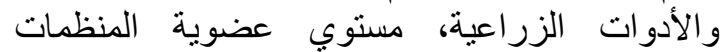

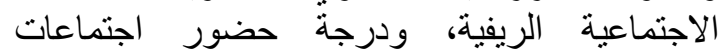

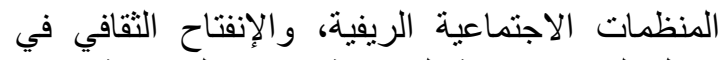
مجال الري، ودرجة التجديدية ( تبني المستحدثات في الرية في فئية

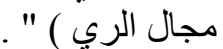

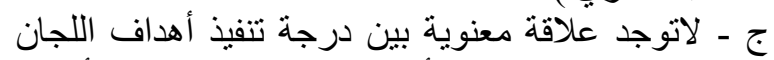

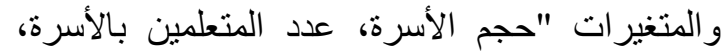

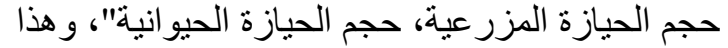

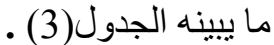
وبصفة عامة توجد علاقة معنوية بين درجة المانة المعرفة

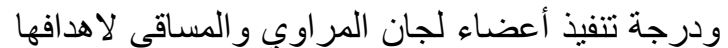

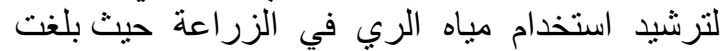

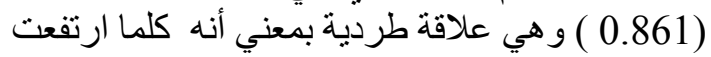

علي ترشيد استخدام مياه الري، والمتغيرات المستقلة المدروسة فقد تم صياغة الفرض الإحصائي التالي :

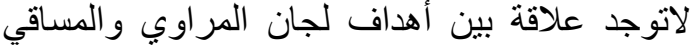
و المتغير ات المستقلة. و لإختبار صحة الإنة الفرض الإحصائي

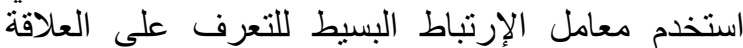

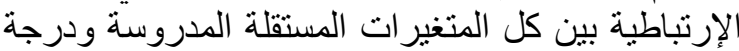

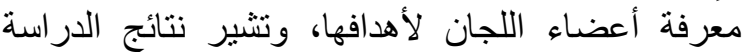

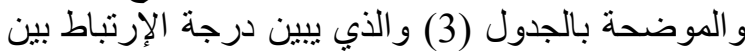

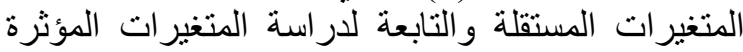

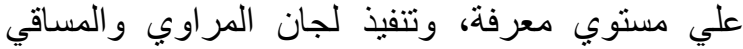
لترشيد استخدام مياه الري ببعض وفيد قري المحافظة إلي

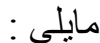
أولا : نتائج اختبار الفرض الإحصائي الأول

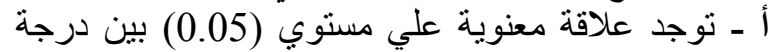

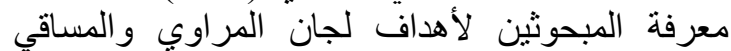

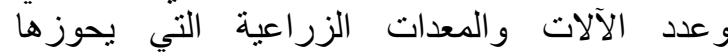

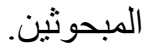

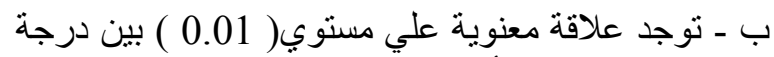

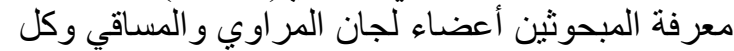

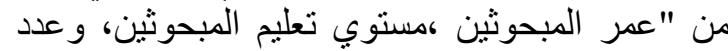

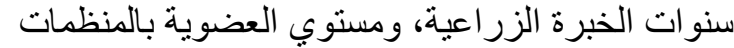

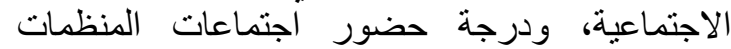
الاجتماعية الريفية، ودرجة إنفتاحهم الثقافي في مجالية الرات الري، ودرجة تجديدية المبحوثين (تبني المبحوثين

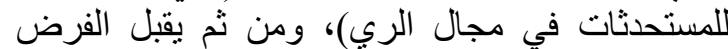

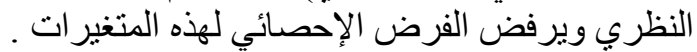

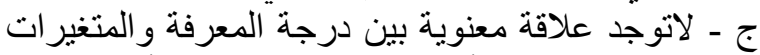

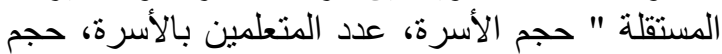

\begin{tabular}{|c|c|c|}
\hline \multicolumn{2}{|c|}{ قيم معامل الإرتباط لمستوي } & \multirow[t]{2}{*}{ المتغيرات المستقلة/ المتغيرات التابعة } \\
\hline تنفيذ الأهداف & معرفة الأهداف & \\
\hline ** 0.199 & $* * 0.258$ & عمر المبحوث \\
\hline$* * 0.223$ & $* * 0.296$ & مستوي تعليم المبحوثين "عددسنوات التعليم" \\
\hline$* 0.180$ & $* * 0.270$ & عدد سنوات خبرة المبحوثين بالزراعة \\
\hline 0.066 & 0.092 & 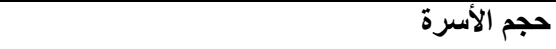 \\
\hline 0.077 & 0.062 & عدد المتعلمين بالأسرة \\
\hline 0.075 & 0.156 & حجم الحيازة المزرعية \\
\hline 0.081 & 0.158 & حجم الحيازة الحيوانية \\
\hline$* * 0.233$ & * 0.197 & حيازة المبحوثين لبعض الآلات والأدوات الزراعية \\
\hline$* * 0.342$ & $* * 0.347$ & مستوي عضوية المنظمات الاجتماعية الريفية \\
\hline$* * 0.474$ & $* * 0.532$ & درجة حضور اجتماعات المنظمات الاجتماعية \\
\hline$* * 0.511$ & $* * 0.459$ & درجة الإنفتاح الثقافي للمبحوثين في مجال الري \\
\hline$* * 0.301$ & $* * 0.321$ & تجديدية المبحوثين \\
\hline
\end{tabular}


لصيانة محطات الري المطور، عدم توفير مياه الري

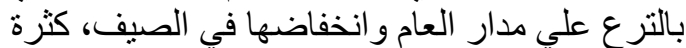

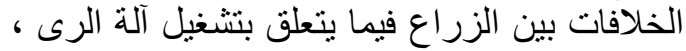

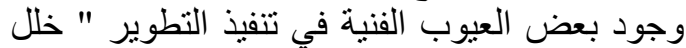
في مناسيب نركيب المواسير "، ارتفاع أسعار قطع تئع الغيار ، و عدم توفير هاب.

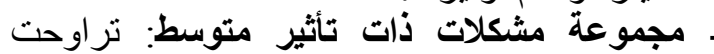

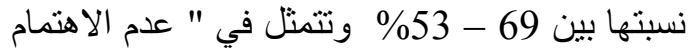

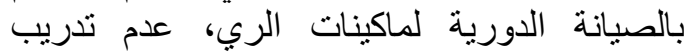

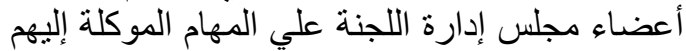

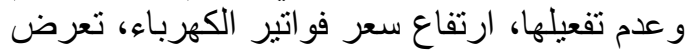

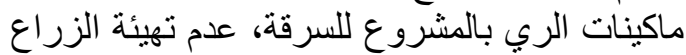

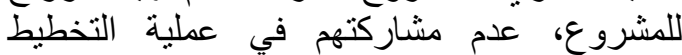
و التنفيذ للمشروع، شعور عاركو الزراع أن المشروع

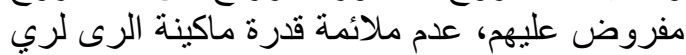

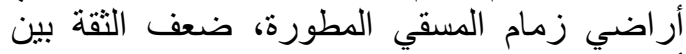
أعضاء مجلس إدارة اللجنة و الزر الزعاع وبين المسئولين

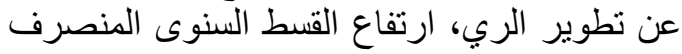

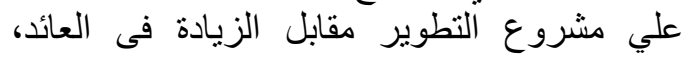
صعوبة تنظيم مو اعيد الري بين الرين الزراع الزيلى على المسقي

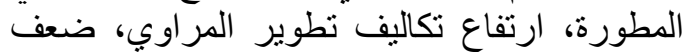

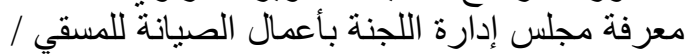

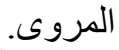

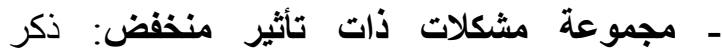

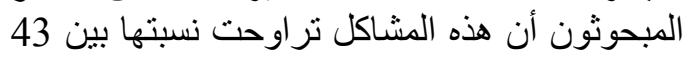

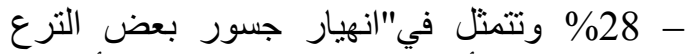

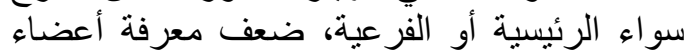

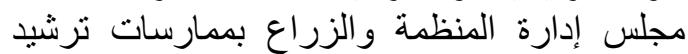
المياه علي مستوي الحقل، وضعف كفاءة نظام الرىى ترن
درجة المعرفة ارتفعت درجة التبني و التنفيذ ومن ثم تعديل

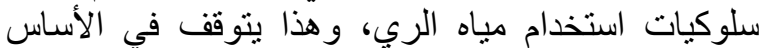

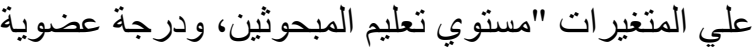

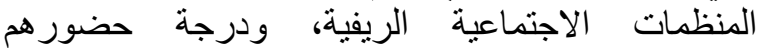

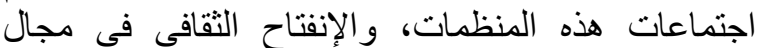
الري، وهذا ما يتفق مع نتائج الفرض الإنفاح الإحصائي الأول.

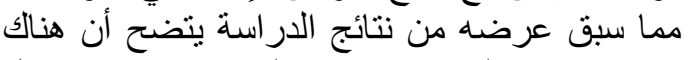

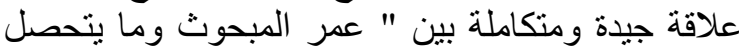

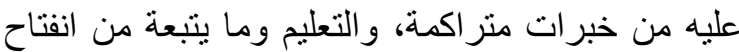

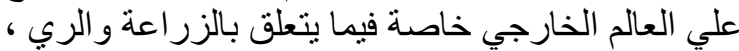

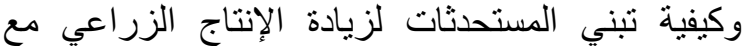

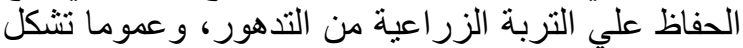

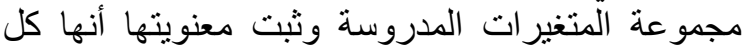

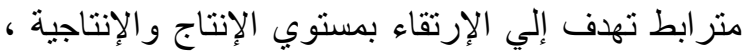

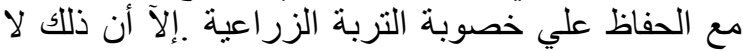

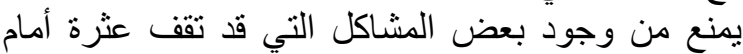
الإرتقاء بمسنوي الإنتاج .

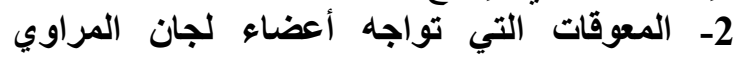

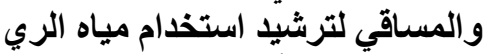

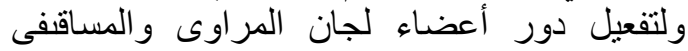

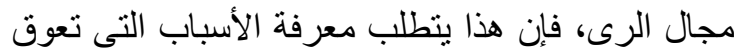

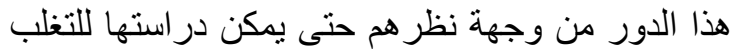

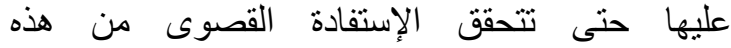

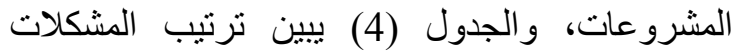

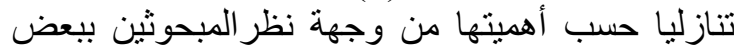
قري محافظة كفر الثيخ، وقد أمكن تقسيم هذه المشكلات

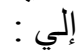

- مجموعة مشكلات ذات تأثير كبير: حيث تراوحت

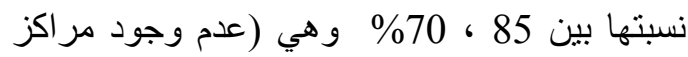

جدول (4): ترتيب المشكلات تنازليا حسب أهميتها من وجهة نظر المبحوثين ببعض قري محافظة كفر الثيخ

\begin{tabular}{|c|c|c|}
\hline$\%$ & العــد العـد & المشكلات( مرتبة تنازليا وفق تكراراتها) \\
\hline 85 & 128 & عدم وجود مر اكز لصيانة محطات الري المطور في المناطق المطورة \\
\hline 78 & 117 & عدم توفير مياه الري بالترع علي مدار العام وانخفاضها في الصيف \\
\hline 75 & 113 & كثرة الخلافات بين الزر اع فيما يتعلق بتشغيل ماكينة الرى \\
\hline 73 & 110 & ارتفاع سعر قطع الغيار و عدم توفير ها \\
\hline 73 & 110 & وجود بعض العيوب الفنية في تنفيذ التطوير (خلل فيمناسيب تركيب المواسير المغطاة ) \\
\hline 72 & 108 & تلف المحابس وسرقتهاو عدم صيانتها \\
\hline 69 & 104 & عدم الاهتمام بالصيانة الدورية لماكينات الري \\
\hline 67 & 100 & عدم تدريب أعضاء مجلس إدارة المنظمات علي المهام الموكلة إليهم و عدم تفعيلها \\
\hline 67 & 100 & ارتفاع سعر فو اتير الكهرباء \\
\hline 66 & 99 & ضعف معرفة مجلس إدارة المنظمة بأعمال الصيانة للمسقي / المروى \\
\hline 65 & 98 & تعرض ماكينات الري بالمشروع للسرقة \\
\hline 63 & 94 & عدم مشاركة الزراع في التخطيط و التنفيذ للمشروع وشعور هم أن المشروع مفروض عليهح \\
\hline 61 & 92 & عدم ملائمة قوة ماكينة الرى للمساحة التي ترويها علي المسقي المطورة \\
\hline 57 & 85 & ضعف التقة بين أعضاء مجلس إدارة المسقي وبين المسئولين عن تطوير الري \\
\hline 56 & 84 & ارتفاع القسط السنوى المنصرف علي مشروع التطوير مقارنةبالزيادة فى العائد \\
\hline 55 & 83 & صعوبة تنظيم مواعيد الري بين الزراع على المسقي المطورة \\
\hline 53 & 79 & رفة مجلس إدارة المنظمة بأعمال الإدارة و التشغيل للمسقي / المروى \\
\hline
\end{tabular}


المشاركة في مشروع تطوير الري بمنطقة نرعة

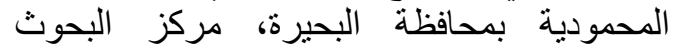
الزراعية، معهد بحوث الإرشاد الزراعية الزئة والتنمية

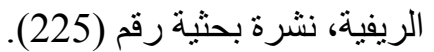

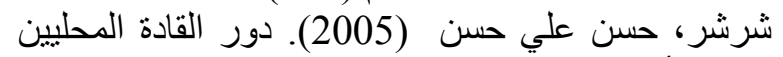

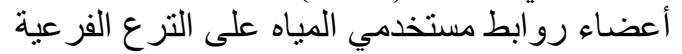

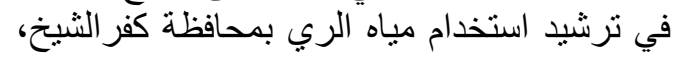

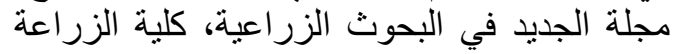
سابا باشا، جامعة الإسكندرية، المجلد (10)، العدد الزداء
الجديد ، ظهور الأملاح علي سطح التربة نتيجة قلة

المياه المستخدمة في الري (الصباغ، 2016 ) ) .

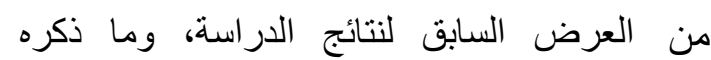
المبحوثون من مشاكل قد يكون لها تأثير علي الإنتاج

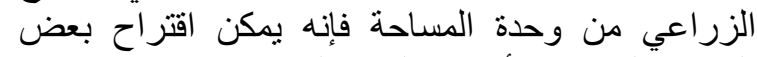

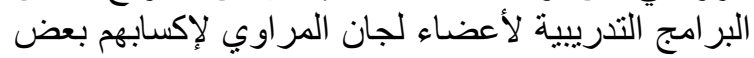

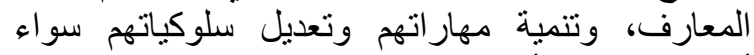
أكانت تخطيطية أو فنية وهي علي النه ونعيل النحو التالي :

الإطار العام لخطة العمل لتفعيل دور اعضاء لجان المراوي والمساقي لترشيد استخدام مياه الري بتنمية معارفهم واكسابهم المهارات التي تحقق

\begin{tabular}{|c|c|c|c|c|}
\hline القترة الزمنية & الفئات المشاركة & الهُف من النشاط & المستهدفون & نوع النشاط \\
\hline 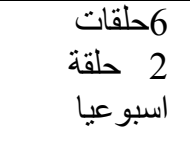 & ختخصراء الري، & 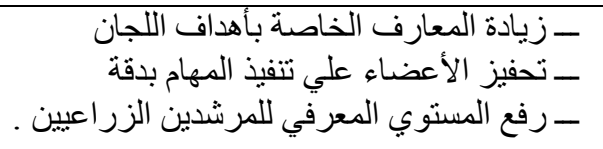 & أعضاء لجان & ونقاتشية \\
\hline أسبوع & 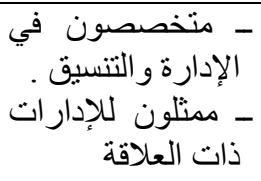 & 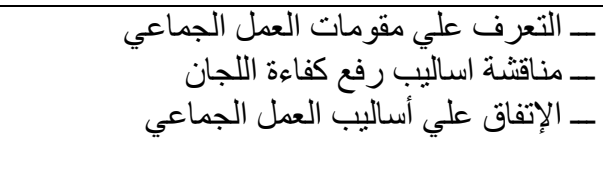 & 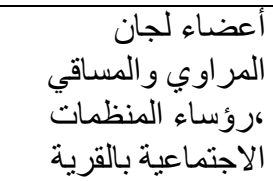 & التنسيق \\
\hline أسبورة & - & 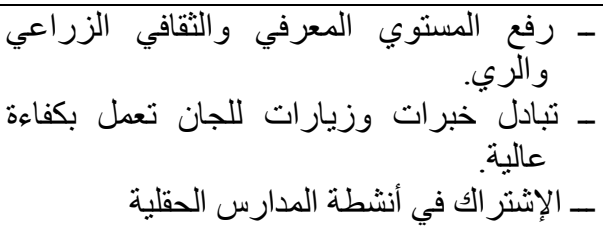 & أمضر اوي ألجان & أرششادية \\
\hline 2 دورة لمدة & 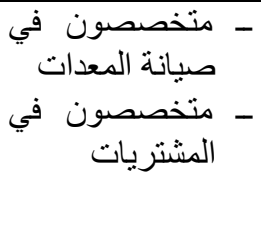 & 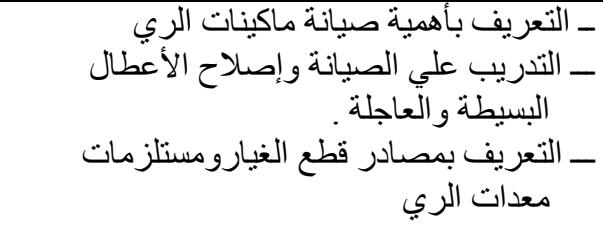 & 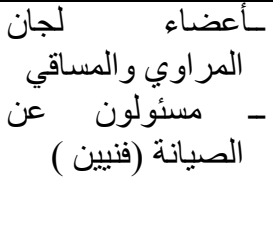 & تعليمية \\
\hline
\end{tabular}

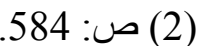

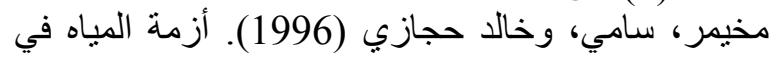

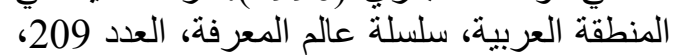
مايو.ص: (47-49).

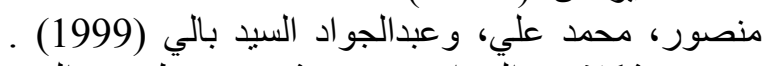

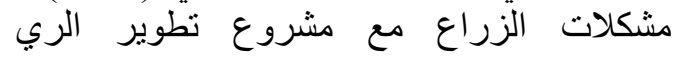

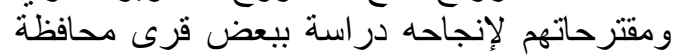

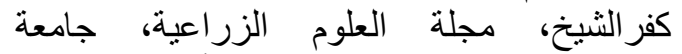

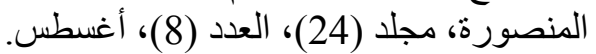
وزارة الزر اعة واستصلاح الأر اضي(2003). استر اتيجية الزية

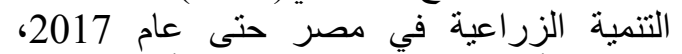
منظمة الأغذية والزراعة الزية (الفاو)- الأمم المتحدة،

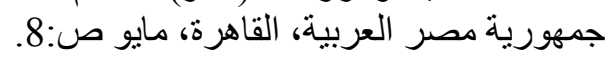

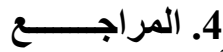

أبو اليزيد الرسول، أحمد (2004). السياسات الاقتصادية

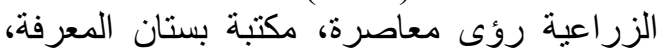

الإسكندرية.ص: (279) (2016).

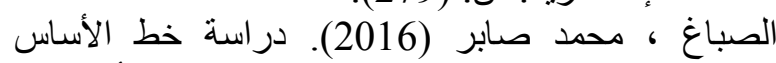

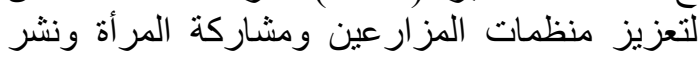

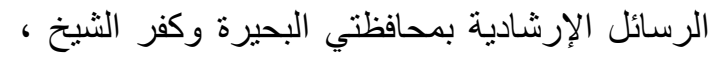

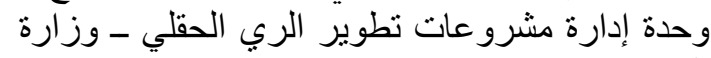

$$
\text { الزراعة إعة مأرة }
$$

بركات ، محمد محمود (2000) ـ الإحصاء الاجتماعي

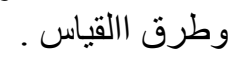

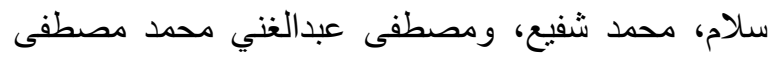
(1999). العوامل المحددة لرفض بعض الزفل 